\title{
CORRESPONDENCE
}

\section{MY SON, THE CAPTAIN}

\author{
Joe Fliegel \\ 714 Crestview Dr., Pinole \\ Ca 94564 / USA
}

There's an old Yiddish joke about a wealthy young man who was fond of dressing up in his captain's uniform and sailing his small boat around the yacht club harbor in calm seas. His mother would proudly tell her friends about "My son, the Captain".

One day, when the weather report predicted high seas he announced he intended to try his hand sailing in rough weather. "But", asked his worried mama, "shouldn't a more experienced sailor go with you?" "Oh, ma, I'm a captain!" "Darling, to me, you're a captain. But to the captains, you're no captain!"

This opening disgression is by way of apologising for my temerity in questioning the assumption of ICCA contributors in general, and the authors of Doubting Castle (March 1991) in particular, that the pinnacle of human chess skill is found in over-the-board grandmaster play. I maintain, instead, it is to be found in correspondence play between postal grandmasters. Here, without the Damocles sword of two-hour time limits constantly leading to errors, minor and major, we have chess at its closest approximation to mortal perfection.

I suppose, even if I'm correct, this does not invalidate the conclusions of typical submissions to ICCA's pages. At worst, it changes a parameter or two. For example, in T.S. Anantharaman's lead article in ICCA for March 1991, he generates numerous statistical measurements based on a population of games from OTB grandmaster play. I expect he would have reached the same conclusions if his selected population had been from postal play, but his standard deviation measurements would have generated smaller numbers. At least if based on identical sample sizes.

\section{HUMAN ARBITERS OF CHESS TACTICS?}

\section{T.S. Anantharaman}

Tudor Investment Corporation
Greenwich, CT

I would like to take this chance to disagree with one of the conclusions attributed to me by the editorial in Vol. 14, March 1991 of the ICCA Journal. The editorial says. "Still and all, Dr. Thomas S. Anantharaman has accumulated enough evidence to show that human GrandMaster play falls short of being a final arbiter of chess excellence".

This is not implied by anything in my thesis and is moreover likely to be misinterpreted to mean that current GrandMasters are no longer capable of judging the play of computers such as Deep Thought. In fact my thesis at most implies that when comparing two different chess programs of the strength of Deep Thought, simply counting the number of times they make the exact same move that the GrandMaster would make, is no longer a reliable guide to which program is stronger. This is not necessarily due to the fact that both programs involved play better than the Grandmaster, but could be simply due to the fact that in many positions there is more than one best (or nearly best) move, and hence the better program might pick the alternate move in such positions.

Furthermore it should be noted that even this behaviour was only observed in Deep Thought when comparing two versions with identical evaluation functions but different search heuristics. In fact, Deep Thought's evaluation function was fine tuned with the object of maximising the number of times Deep Thought's move (with Deep Thought searching only 1-2 plies) agreed with the Grand Master's move.

Hence one can speculate that human GrandMasters fall short of being the final arbiters of chess tactics, though this has not been demonstrated by my thesis. However it seems most unlikely that the positional evaluation of any computer approaches that of a human Expert, let alone that of a Grandmaster.

[The distinction, though very fine, is duly noted. - Eds.] 